\title{
Histopathological Spectrum of Thyroid Lesions- A Two Years Study
}

\author{
Letha Padmom¹, Devi Beena², Kiran Sapru³ \\ ${ }^{1}$ Department of Pathology, Azeezia Institute of Medical Sciences and Research, Kollam, Kerala. India. \\ ${ }^{2}$ Department of Pathology, Azeezia Institute of Medical Sciences and Research, Kollam, Kerala. India. \\ ${ }^{3}$ Department of Pathology, Azeezia Institute of Medical Sciences and Research, Kollam, Kerala. India.
}

\section{ABSTRACT}

\section{BACKGROUND}

In clinical practice, thyroid nodules are very common, with wide disparity in incidence and histopathological pattern related to age, sex, dietary and environmental factors and are usually associated with a wide spectrum of diseases extending from functionally and immunologically mediated enlargement to neoplastic lesions. Thyroid cancer is the commonest endocrine cancer accounting for $92 \%$ of all the endocrine malignancies even though it is a relatively rare malignancy. The aim of this study was to estimate the frequency, age group, sex distribution, and various histopathological spectrum of lesions in the thyroid.

\section{METHODS}

The present study is a hospital based retrospective two-year study and was conducted in the Department of Pathology, Azeezia Medical College, Meeyannor, Kollam, Kerala. Tissue samples for H\&E sections were fixed in $10 \%$ formalin and subjected to routine paraffin embedded processing after which this was then stained with Haematoxylin and Eosin. Various histopathological spectrum of lesions in the thyroid were observed and classified as benign and malignant on the basis of World Health Organization histological classification of the thyroid tumours.

\section{RESULTS}

Out of total cases of 476 thyroid lesions, maximum number of lesions were seen in patients in the age group of 41-50 years. Most common clinical symptom was midline neck swelling. Out of 476 cases, 419 cases (88.1\%) were diagnosed as non-neoplastic and remaining 57 cases (11.9\%) as neoplastic. The most common non-neoplastic lesion was multi-nodular goiter (MNG) (55.4\%), followed by lymphocytic thyroiditis (17.6\%), Hashimoto thyroiditis (9\%), and adenomatous goiter (5.6\%). The common benign lesion was follicular adenoma seen in 17 (29.8\%) cases. Papillary carcinoma was the commonest malignant tumour seen in 33 cases, $66.6 \%$ of all malignant lesions which we encountered in our study.

\section{CONCLUSIONS}

In our study, majority of thyroid diseases showed a female predominance with most of them occurring in the age group of 41-50 years and most common thyroid lesions were non-neoplastic. Proper diagnostic tools, including clinical history, ultrasonography and proper pathological examination are required for the identification of thyroid malignancy. Diagnosis by histopathological examination is important for the prompt diagnosis and treatment of neoplastic lesions.

\section{KEY WORDS}

Thyroid, Thyroiditis, Follicular Carcinoma
Corresponding Author:

Devi Beena,

Assistant Professor

Department of Pathology,

Azeezia Institute of Medical Sciences

and Research, Kollam, Kerala, India.

E-mail: devibeena1987@gmail.com

DOI: $10.14260 /$ jemds/2020/95

Financial or Other Competing Interests: None.

How to Cite This Article:

Padmom L, Beena D, Sapru K. Histopathological spectrum of thyroid lesions- a two years study. J. Evolution Med. Dent. Sci. 2020;9(07):418-421, DOI: 10.14260/jemds/2020/95

Submission 04-11-2019,

Peer Review 21-01-2020,

Acceptance 29-01-2020,

Published 17-02-2020.

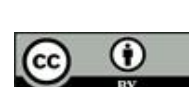




\section{BACKGROUND}

Thyroid gland is one of the important organs in our body and the disorders occurring in thyroid are considered as the most common endocrine disorders seen worldwide. Thyroid gland plays extensive and essential physiological roles in our body. The hormones secreted by the thyroid affect all body organs and are accountable for subsistence of homeostasis and the body integrity. ${ }^{1}$ According to statistics by Salami et al around one-third of the population of the world lives in areas where iodine deficiency is prevalent and account for an estimated 200 million cases worldwide and 42 million cases in India itself. $^{2}$ Thyroid disorders may present as a disorderliness of thyroid hormone secretion, enlargement of thyroid leading to dyspnoea or pain. Worldwide in clinical practice common anomalies are developmental, inflammatory, hyper plastic and neoplastic diseases of thyroid. ${ }^{3}$ Most of the thyroid disorders are benign in nature and thyroid enlargements are seen more common in females than in males. ${ }^{4}$ Thyroid gland disorders usually manifests as enlargement of the thyroid gland (goiters) or as variations in hormone levels or as both. Around $4 \%-5 \%$ of the population present with clinically as externally visible nodules of the thyroid. Majority of the swellings in thyroid are non-neoplastic and around only less than $5 \%$ are malignant ${ }^{5}$. Thyroid carcinoma is a mostly rare malignancy which represents only around $1.5 \%$ of all cancers, but it comprises the most common endocrine carcinoma accounting for about $92 \%$ of all endocrine malignancies. From a clinical point of view, the likelihood of neoplastic disease is of major consternation in those patients who present with nodules in the thyroid. In majority of the thyroid tumours, a diagnosis can be made out by the morphologic evaluation alone; so, the classification of various histomorphological characteristics are important to classify the lesions as benign and malignant tumours. In the evaluation of thyroid lesions the initial screening methods include ultra-sonogram (USG), thyroid function test (TFT), Fine needle aspiration cytology (FNAC), radio nucleotide scan, and among which FNAC is considered to be the best primary diagnostic procedure. ${ }^{6}$ To establish a proper diagnosis, start further therapy and assess the prognosis, surgical excision and pathological evaluation are essential.

This study was undertaken to describe the spectrum, frequency, age, sex distribution and various histopathological patterns of thyroid lesions.

\section{METHODS}

This is a retrospective study of all patients with thyroid lesions received in Department of Pathology, Azeezia Institute of Medical Science and Research, Meeyannoor, Kollam, Kerala. The duration of study was 2 years from 2017 to 2018 were carried out. Information obtained included age, sex, clinical diagnosis, histological diagnosis were available. The data were presented in frequency tables. A Sample Size of 476 subjects was studied. Sample size was taken based on the convenience of the study.

\section{Inclusion Criteria}

Lobectomy, Hemi thyroidectomy, subtotal thyroidectomy and total thyroidectomy specimens received for histopathological examination which were suspected for inflammatory, nonneoplastic and neoplastic lesions of thyroid.

\section{Exclusion Criteria}

1. History of any genetic/ congenital thyroid disease.

2. Antenatal cases having thyroid abnormalities.

3. Thyroid disorders caused due to drug intake/side effects.

\section{Study Subjects}

In this study, a total of 476 patients who presented with swelling in thyroid were taken. The detailed clinical details regarding age, gender along with ultra-sonographic (USG) findings, thyroid scan, related investigations (euthyroid, hyperthyroid, and hypothyroid), and operative findings were recorded from the histopathology Performa and were taken into consideration. Fine needle aspiration was the most commonly used pre-operative assessment method for most thyroid swellings information. Gross features of the specimen received were recorded. Representative tissue was taken and after processing the tissue, routine staining was carried out with haematoxylin and eosin (H\&E) stain. The disorders of thyroid were classified on histological basis into nonneoplastic and neoplastic lesions which were further subclassified as benign and malignant as per the World Health Organization (WHO) classification of tumours of endocrine organs (fourth edition).

\section{Statistical Analysis}

Data was analyzed using Microsoft Excel and chi-square test. Statistical package for social sciences (SPSS) software was used.

\section{RESULTS}

In the present study, a total of 476 patients with thyroid swellings were taken for the study for a period of two years from 2017-2018. The age of the patients ranged from 10 years to 80 years with a mean age of 37 years. Maximum number of lesions were seen in patients in the age group of 41-50 years $(n=139,29 \%)$ followed by 31-40 years $(n=109,21 \%)$ and 21 30 years $(n=57,14 \%)$.

\begin{tabular}{|c|c|c|}
\hline Gender & No. of Cases & Percentage \\
\hline Male & 68 & $14.3 \%$ \\
\hline Female & 408 & $85.7 \%$ \\
\hline Total & 476 & \\
\hline \multicolumn{2}{|c|}{ Table 1. Sex Distribution of Thyroid Lesions } \\
\hline
\end{tabular}

\begin{tabular}{|c|c|c|}
\hline Lesions & No. of Cases & Percentage \\
\hline Non- neoplastic & 419 & $88.1 \%$ \\
\hline Neoplastic & 57 & $11.9 \%$ \\
\hline Total & 476 & 100 \\
\hline \multicolumn{2}{|c|}{ Table 2. Lesions of Thyroid } \\
\hline
\end{tabular}

In the present study, females were mostly commonly affected. It was observed that $408(85.7 \%)$ cases were females and $68(14.3 \%)$ cases were male. (Table 1$)$ Male to female ratio was noted to be $6: 1$. In the present study, most common clinical symptom was swelling in front of the neck seen in almost all cases followed by menstrual irregularity and dyspnoea. In the present study, total thyroidectomies were most common, followed by hemi thyroidectomy specimens, subtotal thyroidectomies and lobectomies. In the present study, out of total 476 cases, 419 cases (88.1\%) were 
diagnosed as non-neoplastic and remaining 57 cases (11.9\%) as neoplastic. (Table 2) In the present study, among 419 cases of non-neoplastic lesions, multi nodular goiter (MNG) 264 cases (55.4\%) was found to be the most common followed by lymphocytic thyroiditis 84 cases (17.6\%), Hashimoto's thyroiditis 43 cases (9\%) and adenomatous goiter 27 cases (5.6\%)and granulomatous thyroiditis. In the present study, benign tumours were more common than malignant tumours. Out of 57 neoplastic lesions 19 cases (33.3\%) were benign tumours and 38 cases $(66.6 \%)$ were malignant tumours. In the present study, among 57 cases of neoplastic lesions, follicular adenoma comprised of 17 cases $-29.8 \%$ was found to be the most common followed by papillary carcinoma which comprises of 33 cases - (57.8\%), follicular variant of papillary carcinoma, 3 cases, follicular carcinoma and non-Hodgkin's lymphoma one case each. In the present study, out of 33 cases of papillary carcinoma, classic variant was seen in 18 cases, followed by micro papillary carcinoma 15 cases.

\section{DISCUSSION}

Anatomically the thyroid gland is located in the neck which is bounded by the pretracheal fascia which is a portion of the deep cervical fascia. It is seen in front of the $2 \mathrm{nd}$, $3 \mathrm{rd}$, and 4 th tracheal rings and weighs around 20-25 gm. ${ }^{7}$ The incidence of the thyroid diseases differ in relation to gender, age groups, and racial differences. ${ }^{8}$ Of all the endocrine disorders, thyroid disorders are the most common in India. ${ }^{9}$ Thyroid lesions may be developmental, inflammatory, hyperplastic and neoplastic. The thyroid gland diseases are common and composed of an array of entities causing systemic disease (grave's disease) or a localized abnormality in the thyroid gland such as nodular enlargement (goiter) or a tumour mass ${ }^{10}$. Both the neoplastic and non-neoplastic diseases of thyroid are common all over the world, with diversity in frequency and incidences depending upon iodine deficiency status. ${ }^{11}$ In our present study, the age of the patients ranged from 10 years to 80 years with a mean age of 47 years which was similar with the study of Arvintham, ${ }^{12}$ Urmila devi et al, ${ }^{13}$ Silverman ${ }^{14}$ et al and which were lower when compared with study conducted by Sathiyamurthy ${ }^{15}$ et al with 36.5 years, et al with mean ages of 44.8 and 46 years respectively.

In our present study the commonest age group presenting with thyroid disorders was in the $4^{\text {th }}$ to 5 th decade which was correlating with the study by sreedevi ${ }^{3}$ et al while study carried out by Jagadale $\mathrm{K}$ et al ${ }^{16}$ and Ramesh V L et al ${ }^{17}$ was found to be 4 th to 6 th decades and 3 rd to 5 th decade respectively. In the present study, it was observed that 408 $(85.7 \%)$ cases were females and $68(14.2 \%)$ cases were male. The female to male ratio found in this study was $6: 1$, which on comparison with the studies by Nzegwu et al,18 Abdulkareem et $\mathrm{al}^{19}$ Sudha et $\mathrm{al}^{20}$ and Nggada et $\mathrm{al}^{21}$ 6:1, 5.7:1, 7:1 and 6.2:1 respectively and was favouring with our study. In women the high frequency of developing thyroid disorders is considered to be due to the physiological demands of puberty, menstruation, pregnancy and lactation. A considerable number of the cases in this study were non-neoplastic thyroid lesions constituting 419 cases (88\%) of the cases. This observed significance of non-neoplastic lesions in our study is in accord with findings from sravani et al, ${ }^{13}$ Chung et $\mathrm{al}^{22}$ and Hill et $\mathrm{al}^{23}$ which was $62.5 \%, 84.1 \%$ and $60.5 \%$ respectively.
In our study the most predominant thyroid lesion encountered is nodular colloid goiter and was commonly seen in the 4 th decade. It constituted $55.4 \%$ of all lesions similar to a study by Illorin ${ }^{24}$ and Sreedevi et al. ${ }^{3}$ Multi nodular goiter (MNG) is the end-stage result of diffuse hyperplastic goiter. Excessive metabolic demands in this condition will lead to the increased enlargement of the thyroid gland and this is one of the important reason for the thyroid enlargement in women during puberty and pregnancy which is considerably common. ${ }^{24}$ Constant stimulation by the TSH released from the anterior pituitary results in multi-nodular goiter (MNG). Main reason for colloid goiter is iodine deficiency. The daily iodine requirement is about $100-125 \mu \mathrm{g}$. It is treated by iodized salt used for food and also iodine-containing preparations. If the iodine deficiency state sustains for a long period of time, it results in the accumulation of colloid material in the gland and lead to colloid goiter. The puberty goiter, pregnancy goiter, and colloid goiter if left untreated will change to MNG. ${ }^{25}$

In our study the lymphocytic thyroiditis constituted 84 cases (17.6\%) and it was seen most common in the 3rd decade. Which was in correspondence with Illorin et al. ${ }^{24}$ Hashimoto thyroiditis constituted 43 cases (9\%) was seen most common in the 4th decade. Hashimoto thyroiditis is an auto immune disease characterized by widespread lymphocytic infiltration, fibrosis and parenchymal atrophy with oxyphilic changes. It is a painless goiter and there are no early symptoms. ${ }^{26}$ In our study, malignant lesions 38 cases (66.6\%) predominated over benign 19 cases $(33.3 \%)$ within the neoplastic category. Our findings in this regard are similar to the study of Beigh et $\mathrm{al}^{1}$ and Abdulkader et $\mathrm{al}^{27}$ who reported, among which $81 \%$ and $88.8 \%$ were malignant respectively.

Among the 57 cases of the neoplastic thyroid lesions in this study, 17 case $(29.8 \%)$ are follicular adenomas which was correlating with Prabha e al. ${ }^{28}$ Follicular adenomas may be inactive or active. Depending on their level of function follicular adenomas can be described as cold, warm, or hot. A thyroid adenoma is differentiated from an MNG in that an adenoma is solitary, encapsulated and arises from a genetic mutation in a single precursor cell. To differentiate a follicular adenoma from follicular carcinoma cautious histopathological examination is necessary. ${ }^{29}$

Papillary carcinoma was the most common malignant thyroid lesion and constituted $57.8 \%$ of the malignant lesions in our study. This observation was similar with the study of Gupta $\mathrm{A}$ et $\mathrm{al}^{30}$ Chukudebelu et $\mathrm{al}^{31}$ and Abdulkader et al. ${ }^{27}$ Papillary microcarcinoma constituted 7 cases $(6.3 \%)$ and was correlating with study by Sreedevi et al. ${ }^{3}$ Histopathologically papillary carcinoma appears as colloid-filled follicles with papillary projections along with psammoma bodies which may be present in calcified lesions. Young females are commonly affected in the age group of 20-40 years. Frequently lymph nodes in the lower deep cervical region may be involved. 32 Thus, the present study gives beneficial knowledge about the epidemiological and demographic variables in regard with the about various thyroid disorders on the basis of histopathology.

\section{CONCLUSIONS}

In our study, thyroid diseases showed definite female predominance, with most of them occurring in an age group of 41- 50 years. Multi nodular goiter is the most common thyroid 
condition which was seen occurring clinically, radiologically, and cytologically. In our study follicular adenoma was the most common benign neoplastic disease and papillary carcinoma was the most common malignant lesion. Fine-needle aspiration findings and ultra-sonogram findings was in consonance with histopathological findings as far as papillary carcinoma was concerned. From this study two important observations that has been noticed were that the nonneoplastic lesions are much more common over the neoplastic lesions and the other is that the malignant lesions are seen predominating the benign lesions and of the malignant lesions papillary carcinoma of thyroid is the major constituent.

\section{REFERENCES}

[1] Beigh A, Amin J, Junaid S, et al. Histopathological study of thyroid neoplastic lesions in a tertiary care hospital - a 5 year study. International Journal of Contemporary Medical Research 2018;5 (4):D4-D7.

[2] Salami BA, Odusan O, Ebili HO, et al. Spectrum and prevalence of thyroid diseases seen at a tertiary health facility in Sagamu, South-West Nigeria. Niger Postgrad Med J 2016;23 (3):137-40.

[3] Sreedevi AR, Sheela KM. Histopathological spectrum of non-neoplastic and neoplastic lesions of thyroid- 2 year study in a tertiary care teaching hospital. JMSCR 2018;6 (6):514-9.

[4] Hudise JY, Alshehri KA, Alqarni SN, et al. Prevalence and pattern of thyroid malignancy in thyroid nodule in Aseer Central Hospital in KSA. Int J Otorhinolaryngol Head Neck Surg 2017;3 (4):908-12.

[5] Sukumaran R, Kattoor J, Pillai KR, et al. Fine needle aspiration cytology of thyroid lesions and its correlation with histopathology in a series of 248 patients. Indian J Surg Oncol 2014;5 (3):237-41.

[6] Zulfikar A, Ritica C, Umaru N. Study of prevalence of thyroid lesions in coastal regions of Karnataka. Journal of Evolution of Medical and Dental Sciences 2013;2 (36):6995-7002.

[7] Shenoy R. Manipal Manual of surgery with clinical methods. Vol. 20. $2^{\text {nd }}$ edn. New Delhi: CBS Publishers and Distributors Pvt. Limited., 2010: p. 311.

[8] Antony J, Celine TM, Chacko M. Spectrum of thyroid disorders a retrospective study at medical college hospital. Thyroid Res Pract 2014;11 (2):55-9.

[9] Kochupillai N. Clinical endocrinology in India. Curr Sci 2000;79 (8):1061-7.

[10] Ananthakrishnan N, Rao KM, Narasimhans R, et al. The single thyroid nodule: a south Indian profile of 503 patients with special reference to incidence of malignancy. Indian J Surg 1993;55 (10):487-92.

[11] Vanderpump MPJ. The epidemiology of thyroid disease. Br Med Bull 2011;99 (1):39-51.

[12] Aravinthan T, Banagala ASK, Gamage KJPK. Use of fine needle aspiration cytology on thyroid lumps. Galle Med J 2007;12 (1):25-7.

[13] Urmiladevi P, Sravani P, Bhagyalakshmi A, et al. Clinicohistopathological study of thyroid lesions in a tertiary care center over a period of one year. J Evid Based Med Healthc 2018;5 (32):2374-9.
[14] Silverman FJ, West RL, Larkin EW, et al. The role of fine needle aspiration biopsy in the rapid diagnosis and management of thyroid neoplasm. Cancer 1986;57 (6):1164-70.

[15] Sathiyamurthy K, Patil MS, Mirje M. Fine needle aspiration cytology study of thyroid lesions. International J Current Res 2014;6 (10):9230-3.

[16] Jagadale K, Srivastava H, Nimburgi R. Recent trends in distribution of thyroid lesions in a tertiary care hospital in India. Ejleps 2016;3 (4):234-9.

[17] Ramesh VL, Shwetha R. Study of distribution of the thyroid lesions in a hospital. International Journal of Science and Research 2014;3 (21):2441-3.

[18] Nzegwu MA, Njeze GE, Olusina DB, et al. A histological update of thyroid lesions in Enugu, Nigeria: a 5 year retrospective study. Asian J Exp Biol Sci 2010;1 (2):1-5.

[19] Abdulkareem FB, Banjo AA, Elesha SO. Histological review of thyroid lesions: a 13 year retrospective study (1989 2001). Niger Postgrad Med J 2005;12 (3):210-4.

[20] Shalini RS, Sudha I. Title - histopathological spectrum of thyroid gland lesions in a tertiary care center- a five year retrospective study. IOSR Journal of Dental and Medical Sciences (IOSR-JDMS) 2019;18 (2):70-3.

[21] Nggada HA, Ojo OS, Adelusola KO. A histopathological analysis of thyroid diseases in Ile-ife, Nigeria: a review of 274 cases. Niger Postgrad Med J 2008;15 (1):47-51.

[22] Chung EB, Rogers N, White JE. Thyroid diseases in Black patients. J Natl Med Assoc 1977;69 (8):573-7.

[23] Hill AG, Mwangi I, Wagana L. Thyroid disease in a rural Kenyan hospital. East Afr Med J 2004;81 (12):631-3.

[24] Adenji KA, Anjorin AS, Ojunsulire A. Histopathological patterns of thyroid diseases in a Nigerian population. Niger Q J Hosp Med 1998;8:241-4.

[25] Office of Dietary Supplements Iodine, 2018 https://www.ods.od.nih.gov/factsheets/Iodine-Health Professional.

[26] Hashimoto's Disease NIDDK. National Institute of Diabetes and Digestive and Kidney Diseases, 2017. https://www.niddk.nih.gov/ healthinformation/endocrine-diseases/ hashimotos-disease.

[27] Albasri A, Sawaf Z, Hussainy AS, et al. Histopathological patterns of thyroid disease in Al-Madinah Region of Saudi Arabia. Asian Pac J Cancer Prev 2014;15 (14):5565-70.

[28] Prabha V, Bhuvaneswari MG. A study of histopathological spectrum of thyroid lesions: an observational study. Int J Sci Stud 2019;7 (1):1-4.

[29] Ramzi SC, Vinay K, Nelson F, et al. Robbins and Cotran Pathologic basis of disease. St. Louis: Elsevier Saunders 2005: p. 11-7.

[30] Gupta A, Jaipal D, Kulhari S, et al. Histopathological study of thyroid lesions and correlation with ultrasonography and thyroid profile in western zone of Rajasthan, India. Int J Res Med Sci 2016;4 (4):1204-8.

[31] Chukudebelu 0, Dias A, Timon C. Changing trends in thyroidectomy. Ir Med J 2012;105 (6):167-9.

[32] Hu MI, Vassilopoulou-Sellin R, Lustig R, et al. Thyroid and parathyroid cancers. In: Pazdur R, Wagman LD, Camphausen KA, et al. eds. Cancer management: a multidisciplinary approach. $11^{\text {th }}$ edn. London: CMP United Business Media 2008. 